\title{
An analysis of thermo-mechanical fatigue crack growth in the titanium alloy Ti-6246
}

\author{
J. Palmer ${ }^{1}$, J. Jones ${ }^{1}$, M. Whittaker ${ }^{1}$, S. Williams ${ }^{2}$ \\ 1. Institute of Structural Materials, College of Engineering, Bay Campus, Swansea University, \\ Swansea, SA1 8EN
}

2. Rolls-Royce plc, PO Box 31, Derby, DE24 8BJ

\begin{abstract}
$\underline{\text { Abstract }}$
Titanium alloys are equipped with impressive high strength and low density, along with other notable mechanical properties. Often the choice for low to intermediate temperature mechanical applications, titanium alloys are well utilised within the aerospace industry, making up $40 \%$ of the aero-engine. Within the gas turbine engine, the high transient thermal stresses developed due to variations in power requirements during a typical flight cycle give rise to the phenomenon of thermo-mechanical fatigue (TMF). The lifing models utilised within this research focus on damage tolerance approaches. TMF crack growth test techniques have been developed for high performance titanium alloys, in which diverse phasing $(\varphi)$ between mechanical loading and temperature have been investigated. In addition, factors affecting the TMF behaviour of Ti-6246, including peak temperature, minimum temperature and temperature range have also been explored.
\end{abstract}

\section{Introduction}

Known for their high strength-to-weight ratio, titanium alloys are often a preferred choice within the aerospace industry for applications with low to intermediate operating temperatures. With the ability to operate at temperatures ranging from sub-zero to $600^{\circ} \mathrm{C}$, they are utilised in the gas turbine engine for both discs and blades from the front fan to the last stage of the high-pressure compressor [1].

The phenomenon of thermo-mechanical fatigue (TMF) is prevalent within the gas turbine engine due to the high transient thermal stresses developed with the power requirements during a typical flight cycle. TMF is the result of combined mechanical and thermal loading cyclically varying with time. The effects of this combined loading can be more damaging by more than an order of magnitude compared with isothermal fatigue at the maximum operating temperature [2]. With the improving efficiency of the gas turbine at the forefront of aerospace research, TMF is an important phenomenon to consider.

TMF testing can be carried out under strain or load control, both of which require the definition of phase angle (between thermal and mechanical strains or stresses) and loading direction. This programme investigates testing under load-controlled conditions where an in-phase (IP) cycle can be defined as having thermal and mechanical stresses increase/decrease concurrently. Tests conducted with a phase angle of $180^{\circ}$, also known as out-of-phase (OP), are defined as having the minimum temperature coincide with the peak stress and vice versa. Thus, there are an infinite number of phase angles between these two extremes and deviating from IP and OP introduces the relevance of loading direction, as this describes whether the loading history on the stress-temperature axes is clockwise $(\mathrm{CW})$ or anti-clockwise $(\mathrm{ACW})$.

With limited research conducted into the TMF behaviour in titanium alloys, the focus of this project seeks to further investigate the complex interaction of creep, oxidation and TMF within the titanium alloy, Ti-6246 (Ti-6Al-2Sn-4Zr-6Mo). Due to their high strength to weight ratio, titanium alloys are favourable for use in the compressor sections of the gas turbine engine. Ti-6246 is an $\alpha+\beta$ alloy, with an evidently different microstructure to Ti-64 (Ti-6Al$4 \mathrm{~V}$ ), displaying a fine Widmanstatten microstructure [3]. Ti-64 has traditionally not been exposed to in-service temperatures above $350^{\circ} \mathrm{C}$ and therefore typically high temperature damage mechanisms, such as creep, have not been perceived to be a critical issue [4]. However, with the continuing desire to increase the operating temperatures of the gas turbine, alloys such as Ti-6246 and Ti-834 (Ti-5.8Al-4Sn-3.5Zr-0.7Nb-0.5Mo) are being widely used at higher temperatures [5]. It is therefore becoming increasingly more important to ensure research is carried out to gain a full understanding of the behaviour of the material.

The purpose of this research is therefore to investigate the behaviour of Ti-6246 under TMF conditions to allow for a more representative understanding of its behaviour during in-service conditions, particularly within the gas turbine. 


\section{Experimental Procedures}

As previously mentioned, the material studied throughout this investigation is titanium alloy, Ti-6Al-2Sn-4Zr-6Mo (Ti-6246). Corner-crack specimens with nominal dimensions of $7 \times 7 \mathrm{~mm}$ and a parallel gauge length of $20 \mathrm{~mm}$ were used. A starter slit of $0.35 \mathrm{~mm}$ was introduced to enable the crack to initiate at that position. Thermal profiling and preliminary isothermal fatigue crack growth (IFCG) tests were conducted prior to the completion of the TMFCG test programme.

For the purpose of the TMFCG research, an ESH 100kN servo-hydraulic test machine with a ZwickRoell control cube servo controller and Cubus software system was used. Application of the thermal cycle was achieved using an internally water-cooled induction coil for heating and four Meech air amplifiers were used to provide sufficient, uniform cooling. Using type-N thermocouples, the temperature is controlled and monitored through Dirlik DCPD-TMF software. The final setup is shown in Figure 1.

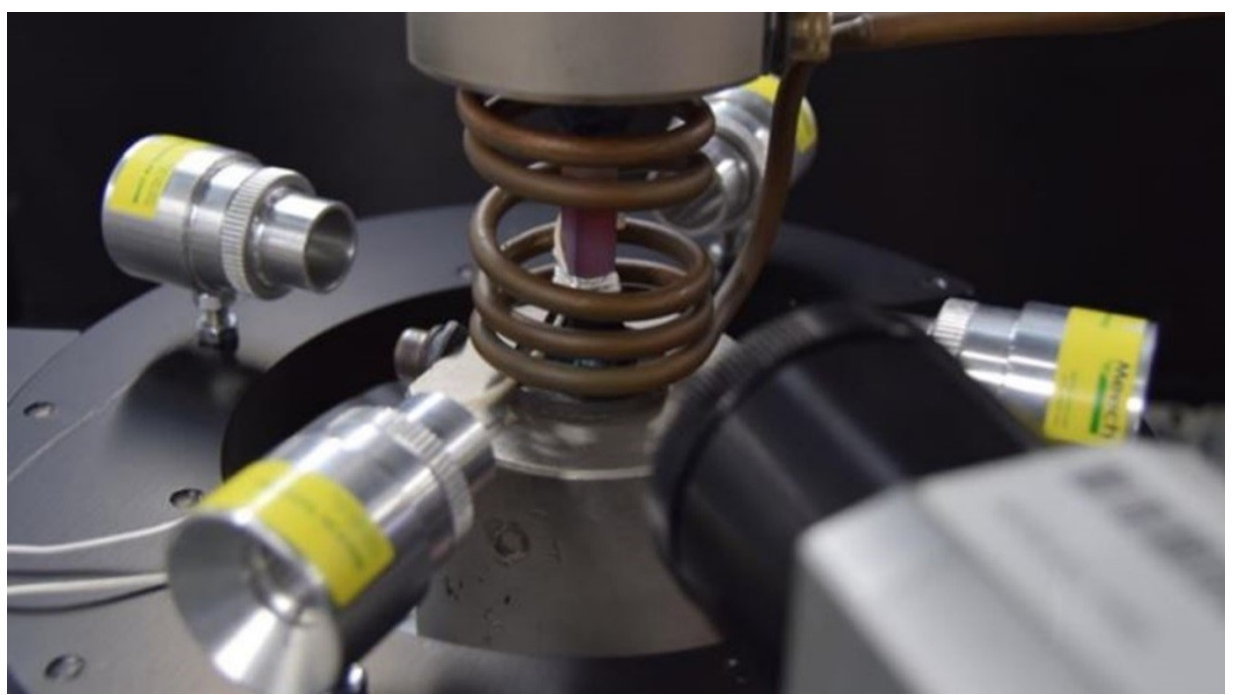

Figure 1: Final setup utilised for TMF CG testing. As shown, a more uniform induction coil is adopted for the heating and four air amplifiers, situated on a platform, are used for the cooling. Also integrated is an infra-red camera

Crack monitoring was conducted using the direct current potential drop (DCPD) method. The DCPD method works on the principle of an occurrence of a discontinuity in a specimen being recorded when a homogeneous current of an adequate value is passed through the whole cross section of the specimen, causing a potential drop. This method has been tested and proven acceptable for monitoring crack propagation and thus, has been adopted for this research and is monitored through Dirlik DCPD-TMF software.

As thermocouples are spot-welded to the specimen during testing, pre-cracking is particularly important, not just to relieve any residual stresses from the machining of the notch but also to eliminate the possibility of the test piece experiencing multiple crack initiation sites. In order to ensure this, a loadshedding pre-cracking procedure is conducted at room temperature pre-test, without the presence of thermocouples, for all tests.

IFCG tests were conducted at $500^{\circ} \mathrm{C}, \mathrm{R}=0$ and were load-controlled with a maximum stress of $500 \mathrm{MPa}$ using both a conventional radiant furnace and an induction coil for the source of heating. The waveform adopted for such tests was a standard trapezoidal 1-1-1-1 waveform. These preliminary tests were conducted to provide a comparison between the two heating methods and to aid the validation of the induction coil as a viable heating method.

Both IP and OP TMFCG tests have been carried out with test conditions of a stress ratio, $\mathrm{R}=0$, maximum stress of 500MPa and temperature ranges of 200$500^{\circ} \mathrm{C}$ and $200-550^{\circ} \mathrm{C}$. The waveform adopted for the TMFCG testing in this programme was a triangular waveform with a frequency of $0.0125 \mathrm{~Hz}$.

\section{$\underline{\text { Results \& Discussion }}$}


As there is currently no established code of practice for TMFCG testing, the temperatures during testing have been aligned with the existing straincontrolled test standards [6]. Pre-test verification of the test setup was conducted, and a thermal profile was recorded. This was achieved by isolating the temperature and recording/monitoring the thermal cycle using type- $\mathrm{N}$ thermocouples.

Six thermocouples were welded to the gauge of the specimen, as shown in Figure 2. Thermocouples TC1-TC3 were located along the lateral centre of the gauge with a $2 \mathrm{~mm}$ distance between each thermocouple and TC4-TC6 were located at the gauge centre of the other faces. Figure 2 shows that the thermal profile achieved conforms to the validated code of practice for stress-controlled TMF testing, which states that the temperature at the centre of the gauge section should be controlled with an accuracy of $\pm 5^{\circ} \mathrm{C}$ and the axial temperature gradients within the gauge length should not exceed $\pm 10^{\circ} \mathrm{C}[7]$.

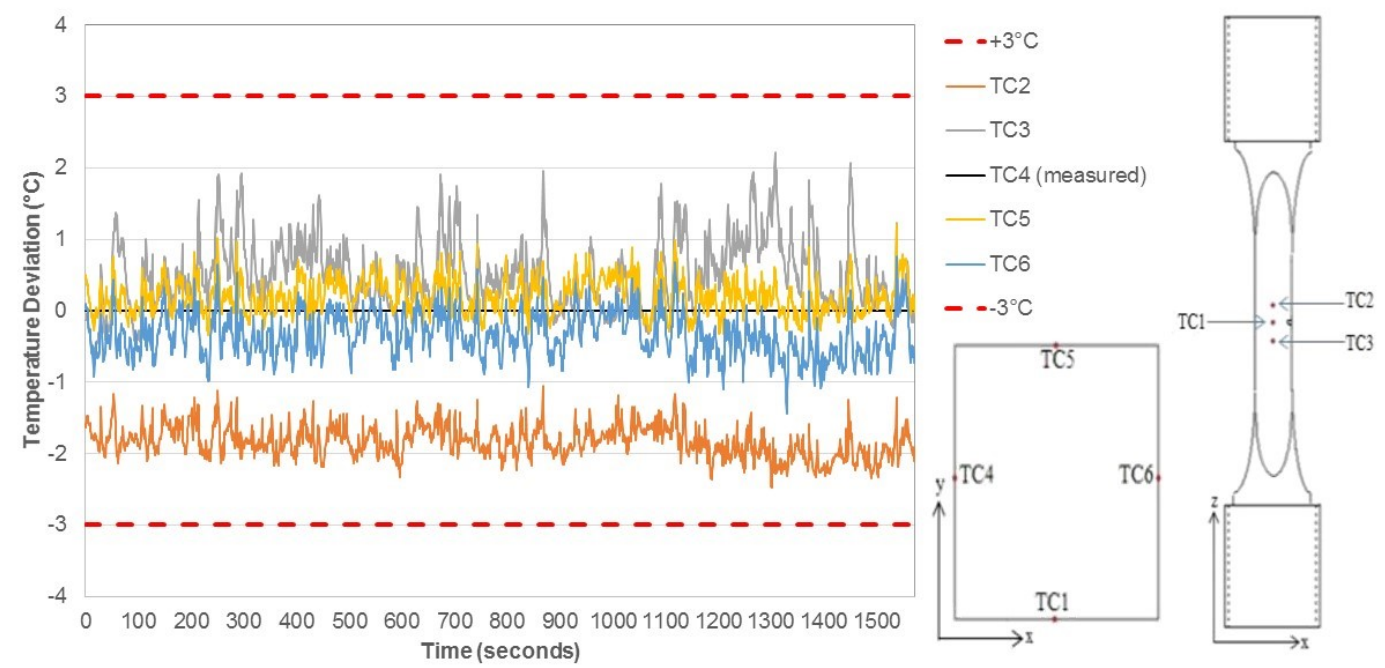

Figure 2: Temperature distribution associated with non-uniform multi-turn longitudinal field helical coil, showing a spread of less than $+/-3^{\circ} \mathrm{C}$ in temperature across the critical volume of material around the crack [8]

Preliminary IFCG tests were conducted to validate the ICS as a viable heating source, as well as DCPD as a reliable crack monitoring technique. There is only limited research in which these two methods have been used in conjunction due to the controversy around potential interference from the ICS on the DCPD crack monitoring [9]. However, Pretty (2014) utilised an ICS and adopted the DCPD for crack monitoring in TMFCG testing of nickel alloys and was able to conclude that such a setup is compatible for both IFCG and TMFCG [10]. The results of the preliminary investigation conducted within this research are displayed in Figure 3. 


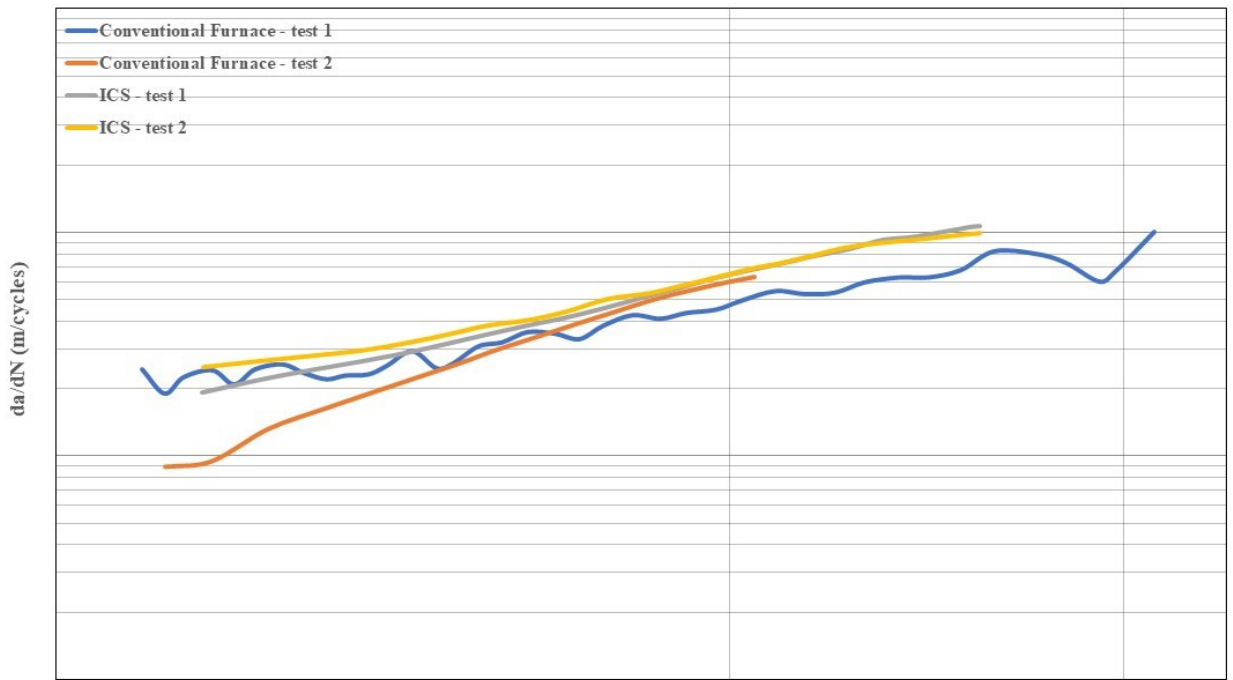

$\Delta \mathbf{K}(\mathbf{M P a} \sqrt{ } \mathbf{m})$

Figure 3: Paris curves comparing isothermal tests conducted using a conventional furnace and ICS

Unlike the conventional furnace, an ICS can provide faster heating rates that are required during a TMF test. It is therefore important to ensure that such a system is validated. Figure 3 displays the crack growth rate against the stress intensity range for the IFCG tests conducted. As can be seen from the results displayed, the results follow a similar trend and are within a reasonable degree of scatter from each other. In undertaking this comparison, it is evident that the ICS, along with the DCPD technique, does in fact provide repeatable, valid results.

With the baseline isothermal data presented, it is possible to compare and rationalise the IP and OP TMFCG results, displayed in Figure 4. 


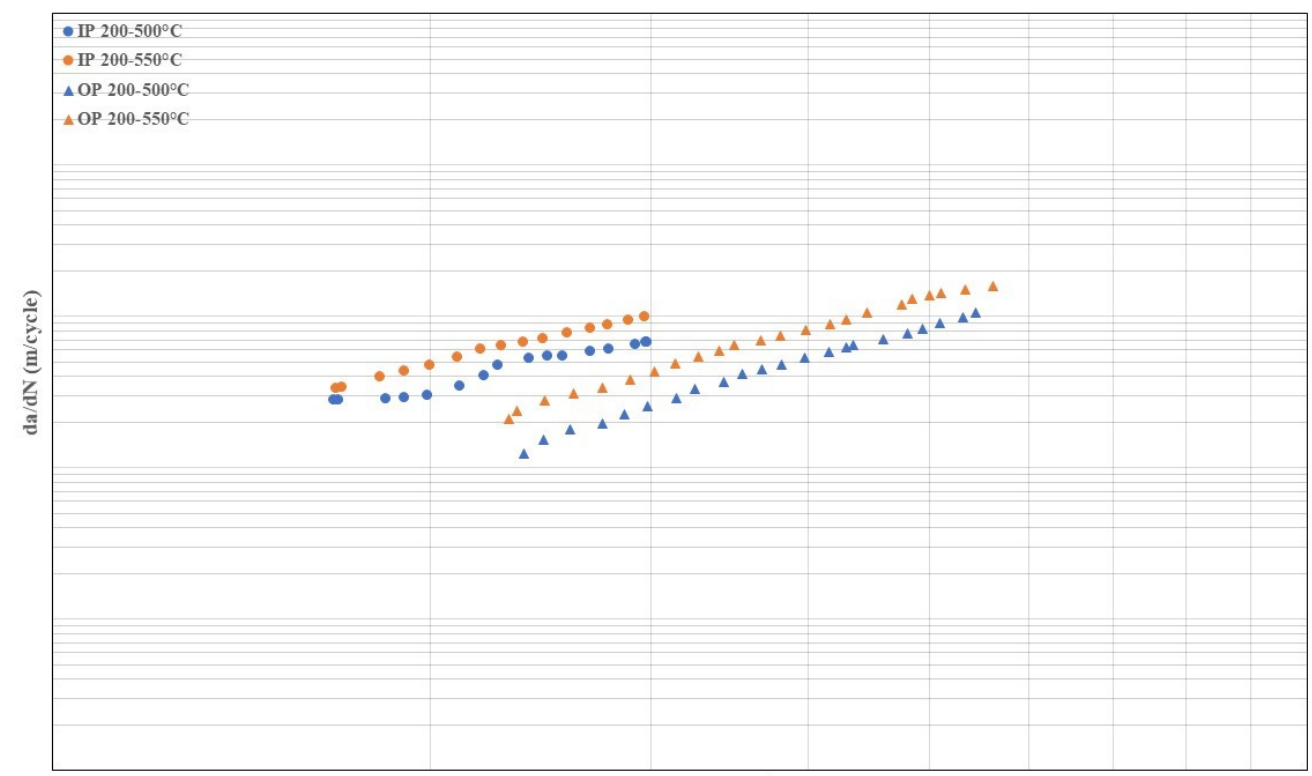

$\Delta \mathbf{K}(\mathbf{M P a} \sqrt{ } \mathbf{m})$

Figure 4: Paris curves comparing TMFCG IP and OP tests conducted with temperature cycles $200-500^{\circ} \mathrm{C}$ and $200-550^{\circ} \mathrm{C}$

Comparing the IP TMF test results to the OP TMF test results at $200-500^{\circ} \mathrm{C}$, it is evident that when testing IP, the crack growth rate is faster than when testing OP. This is as expected since during IP testing, the specimen is exposed to maximum stress and temperature at the same time, which is more damaging to the fatigue life. The crack growth rates increased for both IP and OP tests with a thermal cycle of $200-550^{\circ} \mathrm{C}$, as can be expected due to the higher $\mathrm{T}_{\text {MAX }}$.

Figure $5 \mathrm{a}$ and $5 \mathrm{~b}$ compare the IFCG with the TMFCG results. It should also be noted that the IFCG tests are conducted at a frequency of $0.25 \mathrm{~Hz}$, whereas the TMFCG tests are conducted at a frequency of $0.0125 \mathrm{~Hz}$, thus a much slower cycle and as shown in Figure $5 \mathrm{a}$, at $\mathrm{T}_{\mathrm{MAX}}=500^{\circ} \mathrm{C}$, the slower $\mathrm{TMF}$ cycle is more damaging, presenting a faster crack growth rate. Pretty (2014) investigated the effects of cycle time and concluded that although the temperature varies in the TMF test, the slow cycle results in the material being exposed to higher temperatures for a longer period than that during the IF test. This therefore allows time dependent damage mechanisms, such as oxidation and creep, to take effect and ultimately increase the crack growth rate [11].

However, Figure $5 \mathrm{~b}$ shows that the crack growth rates are more similar for the $550^{\circ} \mathrm{C}$ IFCG and $200-550^{\circ} \mathrm{C}$ TMFCG tests than the $500^{\circ} \mathrm{C}$ IFCG and 200 $500^{\circ} \mathrm{C}$ TMFCG tests. Previous research, carried out by Evans et al. (2005), concluded that when exposed to temperatures over $500^{\circ} \mathrm{C}$, oxidation becomes the dominating damage mechanism in Ti-6246 [12]. This, therefore, could explain the reason for the lack of effect of phasing in the TMFCG tests where $\mathrm{T}_{\text {MAX }}=550^{\circ} \mathrm{C}$. 


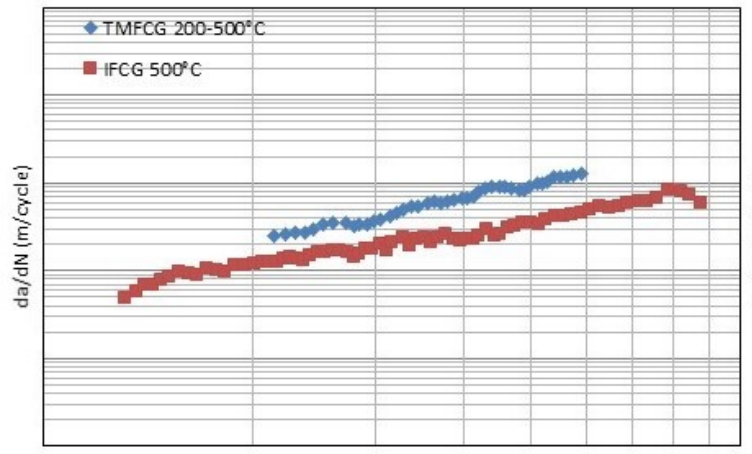

$\triangle \mathrm{K}(\mathrm{MPaVm})$

a)

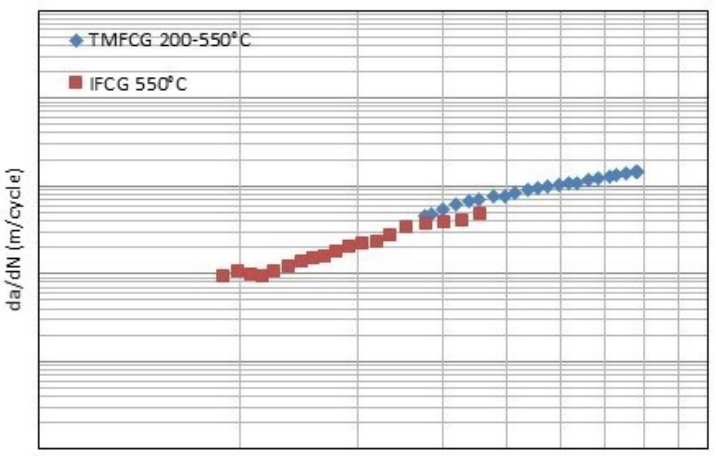

$\Delta \mathrm{K}(\mathrm{MPaVm})$

b)

Figure 5: Paris curves comparing a) IFCG $500^{\circ} \mathrm{C}$ and TMFCG IP $200-500^{\circ} \mathrm{C}$ b) IFCG $550^{\circ} \mathrm{C}$ and TMFCG IP $200-550^{\circ} \mathrm{C}$

Analysing the fracture surfaces of the different specimens, as shown in Figure 6a-c, it is evident that whether the material is tested isothermally or under TMF loading, it does not appear to affect the fracture mechanism, with all test pieces presenting as transgranular fractures. This suggests that Ti-6246 does not experience the same mechanism change nickel superalloys do when tested at different test conditions, particularly different phase angles, as identified in research carried out by Jones et al. [13].

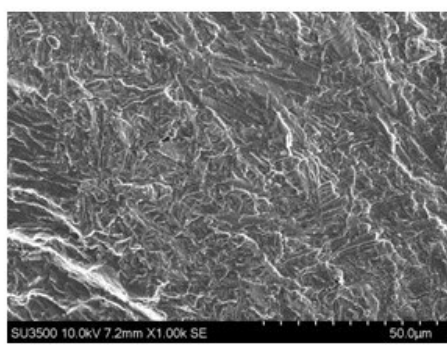

a)

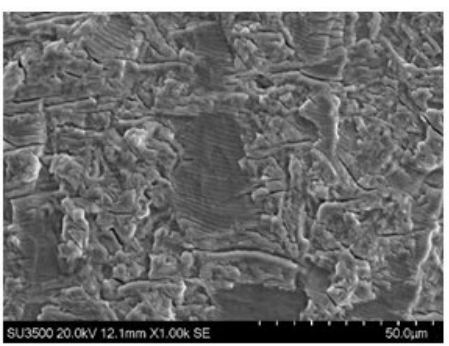

b)

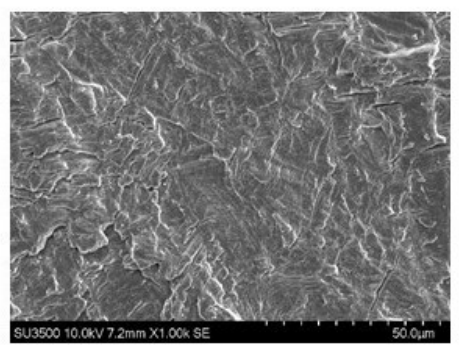

c)

Figure 6: Fractography of a) IFCG $500^{\circ} \mathrm{C}$ b) TMFCG IP $200-500^{\circ} \mathrm{C}$ and c) TMFCG OP $200-500^{\circ} \mathrm{C}$, all of which show transgranular cracking

\section{Conclusions}

TMFCG testing is paramount to understanding the in-service behaviour of Ti-6246 and enabling accurate lifing models to be developed. The research outlined in this paper has provided a technique that will be crucial to the development of in-service lifing of titanium alloys and the following conclusions can be drawn:

- Comparing IF tests conducted in the conventional furnace and ICS, it is evident that both methods result in similar and comparable fatigue crack growth rates. This helps validate the use of the ICS for TMF testing. 
- It is also evident, upon comparing the IF and TMF results, that cycle time appears to affect the crack growth rate, with a slower cycle time being more damaging due to the longer exposure time at high temperatures.

- Fractography shows that there is no change in fracture mechanism, despite the test conditions. This is unlike what has been reported in nickel superalloys.

\section{$\underline{\text { Acknowledgements }}$}

The current research was funded under the EPSRC Rolls-Royce Strategic Partnership in Structural Metallic Systems for Gas Turbines (grants $\mathrm{EP} / \mathrm{H} 500383 / 1$ and EP/H022309/1). The provision of materials and supporting information from Rolls-Royce is gratefully acknowledged. Mechanical tests were performed at Swansea Materials Research and Testing Ltd. (SMaRT). Thanks to Turan Dirlik for DCPD technical development.

\section{References}

[1] AZoM. Titanium alloys for aeroengine and airframe applications [Internet]. 2002 [cited 2019 Mar 22]. Available from: http://www.azom.com/article.aspx?ArticleID=1569

[2] eFatigue LLC. Thermomechanical technical background [Internet]. 2008 [cited 2019 Mar 7]. Available from: https://www.efatigue.com/hightemp/background/tmf.html

[3] Titanium engineers. Titanium 6Al-2Sn-4Zr-6Mo Ti 6246 (UNS R56260). Texas: Titanium engineers; 2016.

[4] MT. Whittaker, Titanium in the gas turbine engine. Advances in gas turbine technology. 2011. p. 315-36.

[5] RM. Nageswara, AD. Kumar, S. Sathyanarayanan, SD. Gupta. Gas turbine materials - current status and its developmental prospects - a critical review. Vellore.

[6] P. Hähner, E. Affeldt, T. Beck, H. Klingelhöffer, M. Loveday, C. Rinaldi. Validated code-of-practice for thermo-mechanical fatigue testing. 2006.

[7] S. Brookes, A. Scholz, M. Whittaker, M. Loveday, A. Wisby, N. Ryder et al. Code of practice for force-controlled thermo-mechanical fatigue testing. 2015.

[8] J. Palmer, J. Jones, A. Dyer, R. Smith, R. Lancaster, M. Whittaker. Development of test facilities for thermo-mechanical fatigue testing. Int J Fatigue. Elsevier; 2019;121:208-18.

[9] L. Jacobsson, C. Persson, S. Melin. Thermo-mechanical fatigue crack propagation experiments in inconel 718. Int J Fatigue. Elsevier; 2009;31(89):1318-26.

[10] CJ. Pretty, MT. Whittaker, SJ. Williams. Crack growth of a polycrystalline nickel alloy under tmf loading. 2016.

[11] CJ. Pretty, MT. Whitaker, SJ. Williams. Thermo-mechanical fatigue crack growth of RR1000. 2017.

[12] WJ. Evans, JP. Jones, S. Williams. The interactions between fatigue , creep and environmental damage in Ti 6246 and Udimet 720 Li. $2005 ; 27: 1473-84$.

[13] J. Jones, M. Whittaker, R. Lancaster, S. Williams. The influence of phase angle, strain range and peak cycle temperature on the TMF crack initiation behaviour and damage mechanisms of the nickel-based superalloy, RR1000. Int J Fatigue. Elsevier; 2017;98:279-85. 